Carlos Roberto DALECK ${ }^{1}$ Julio Carlos CANOLA ${ }^{1}$ Sandro Alex STEFANES ${ }^{1}$, Pablo Felipe Leoz

SCHOCKEN $^{2}$

Andrigo Barboza DE

NARDI ${ }^{1}$

Correspondência para: CARLOSROBERTODALECK

Departamento de Clínica e Cirurgia Veterinária da UniversidadeEstadual Paulista ViadeAcesso Prof. Paulo Donato Castelani, sn 14870-000 - Jaboticabal - SP daleck@fcav.unesp.br

Recebido para publicação: 07/04/2004 Aprovado para publicação: 13/07/2005

\title{
Estudo retrospectivo de osteossarcoma primário dos ossos da pelve em cães em um período de 14 meses
}

1 -Departamento de Clínica e Cirurgia Veterinária da Faculdade de Ciências Agrárias e Veterinárias da Universidade Estadual Paulista, Jaboticabal - SP 2 - Médico Veterinário Autônomo

\section{Resumo}

O osteossarcoma (OSA) é um dos tumores malignos mais comum em cães. Geralmente acomete cães de raça grande e gigante, com idade média de sete anos. Esta neoplasia envolve, freqüentemente, a metáfise de ossos longos, sendo indicado à amputação radical do membro, acrescido de quimioterapia com cisplatina. A terapêutica desta neoplasia com localização na pelve torna-se difícil e normalmente não aceita pelos proprietários. O presente trabalho relata a incidência de osteossarcoma primário em ossos da pelve em cães, durante um período de 14 meses. Dos oito animais atendidos com esta neoplasia, observou-se maior freqüência nos cães da raça Rottweiler e Pastor Alemão. Dentre os ossos que compõem a pelve do animal se observou maior incidência de OSA acometendo o ílio (6 casos). Claudicação, impotência funcional de membro pélvico e dor foram os principais sinais clínicos observados. Em sete casos encontrou-se estágio avançado de comprometimento ósseo na imagem radiográfica, evidenciado, principalmente, pela lise da cortical óssea. Todos os animais foram submetidos à eutanásia por não apresentarem possibilidade de tratamento cirúrgico (hemipelvectomia) com margem de segurança. Também se levou em consideração para esta decisão à condição clínica dos pacientes, as chances de conferir melhora na qualidade de vida dos cães e a opção dos proprietários frente ao prognóstico.

\section{Introdução}

O osteossarcoma (OSA) ou sarcoma osteogênico é a neoplasia óssea primária mais freqüentemente diagnosticada no cão ${ }^{1}$ e representa em torno de $85 \%$ das neoplasias com origem no esqueleto $2,3,4,5$. Fibrossarcoma, hemangiossarcoma, tumor de células gigantes, lipossarcoma, linfoma, osteoma, mieloma múltiplo e condrossarcoma respondem pelo restante, sendo que, destes, o condrossarcoma é relatado com maior freqüência ${ }^{6,7}$.

A etiologia do OSA canino permanece desconhecida, contudo, especula-se a origem viral desta neoplasia, já que pode ocorrer em ninhadas e pode ser induzido experimentalmente pela injeção de células neoplásicas em fetos caninos. Porém, ainda não se isolou nenhum vírus responsável pelo surgimento do OSA canino ${ }^{5}$. Outra teoria é baseada na evidência de que o osteossarcoma tende a ocorrer nos ossos que sustentam os maiores pesos e em sítios adjacentes as fises de fechamento tardio, e, que esses animais de grande porte são predispostos a pequenos e múltiplos traumas nas regiões metafisárias, as quais são de maior atividade celular. A sensibilização de células nesta região pode iniciar a doença pela indução de sinais mitogênicos, aumentando a probabilidade de desenvolvimento de linhagem mutante ${ }^{5}$.

Geralmente os osteossarcomas acometem cães de meia idade, com média de sete anos ${ }^{5,8,9}$. As raças que freqüentemente desenvolvem esta neoplasia são o São Bernardo, Dinamarquês, Setter Irlandês, Dobermann, Pastor Alemão, Rottweiller e 
Golden Retriever ${ }^{10,11,12}$. Em relação à distribuição anatômica, $75 \%$ dos osteossarcomas desenvolvem-se no esqueleto apendicular e $25 \%$ no esqueleto axial $1^{13,14}$. Em estudo realizado por Heymann et al. ${ }^{13}$, de 116 casos de OSA canino primário no esqueleto axial, $27 \%$ localizavam-se na mandíbula, $22 \%$ na maxila, $15 \%$ nas vértebras, $14 \%$ no crânio, $10 \%$ nas costelas, $9 \%$ na cavidade nasal e $6 \%$ na pelve. Segundo Pool $^{15}$ cães machos apresentam incidência desta neoplasia uma vez e meia maior do que as fêmeas; porém, quando os casos são de osteossarcoma do esqueleto axial, as fêmeas são mais acometidas que os $\operatorname{machos}^{13,16}$.

O OSA é uma neoplasia extremamente agressiva, tanto no local do crescimento quanto na formação de metástases ${ }^{8,17}$. As metástases são muito comuns e geralmente estão presentes na forma subclínica no início da doença. Menos que 15\% dos cães possuem sinais de metástases pulmonares radiograficamente detectáveis no momento do diagnóstico do OSA primário, porém 90\% destes animais morrerão pelo desenvolvimento de metástases no pulmão com menos de um ano de sobrevida quando a intervenção cirúrgica for a única forma de tratamento ${ }^{12}$.

O diagnóstico é baseado na anamnese, exame físico, achados radiológicos, cintilografia óssea e tomografia computadorizada sendo a confirmação feita através de biópsia e exame histopatológico ${ }^{8,9,15,18}$. Os sinais clínicos em cães acometidos pelo OSA variam entre dor, claudicação, aumento de volume, tumefação, edema e fraturas espontâneas ${ }^{3}$. A dor é resultado de microfraturas ou à interrupção do periósteo induzido pela lise óssea proveniente do desenvolvimento neoplásico ${ }^{5,10}$. Jongeward ${ }^{19}$ acrescenta que tremores e atrofia muscular por desuso, dificuldade em se levantar, incontinência urinária e fecal, letargia e anorexia também têm sido observadas em pacientes com osteossarcoma no esqueleto axial.

Ao exame radiográfico inúmeras alterações podem ser observadas, porém a lise de cortical é o achado mais freqüente, podendo ser severa o suficiente para promover áreas de descontinuidade do córtex causando fraturas espontâneas ${ }^{3}$. Radiografias torácicas devem ser realizadas antes do tratamento com o objetivo de detectar doença metastática. Essas radiografias devem ser feitas durante a inspiração e devem incluir três projeções: ventro-dorsal ou dorso-ventral e lateral esquerda e direita. Os nódulos metastáticos de OSA são formados de tecido denso e só podem ser visibilizados, ao exame radiográfico, quando apresentam diâmetro maior que 6 a $8 \mathrm{~mm}^{5}$. No entanto, exames como tomografia computadorizada e ressonância magnética permitem o diagnóstico muito mais precoce das lesões metastáticas ${ }^{5,20}$.

Quando se suspeita de lesão primária óssea neoplásica, deve-se realizar diagnóstico diferencial entre osteomielite bacteriana ou fúngica, infarto ósseo, osteopatia hipertrófica, hipervitaminose $A$, reações periostais traumáticas e cistos ósseos aneurismais ${ }^{20,21}$. O diagnóstico definitivo de neoplasia óssea requer biópsia incisional do tecido tumoral e correta interpretação do tecido pela histopatologia ${ }^{10,22,23}$. A biópsia incisional permite a obtenção de quantidade ideal de tecido e maior precisão do resultado, porém essa técnica apresenta como desvantagens o envolvimento de procedimento cirúrgico, risco de complicações pós-cirúrgicas como formação de hematoma, infecção, disseminação do tumor e fratura patológica ${ }^{23}$.

Para as neoplasias com localização na pelve, a hemipelvectomia parcial ou total como tratamento, embora seja um procedimento cirúrgico agressivo, pode ser realizada com sucesso em cães e gatos ${ }^{3}$. Mesmo quando inevitável muitos propri-etários se mostram relutantes em aceitar a indicação da amputação de algum membro do paciente, e devem ser informados da habilidade deste em se adaptar à locomoção com o uso de três membros ${ }^{24}$. O presente trabalho tem como objetivo relatar a incidência de osteossarcoma primário em ossos da pelve 
de cães, durante um período de 14 meses.

\section{Materiais e Métodos}

Durante o período compreendido entre março de 2002 e maio de 2003, oito pacientes da espécie canina com OSA primário em ossos da pelve foram atendidos pelo Serviço de Oncologia. Como procedimento de rotina realizou-se a anamnese, exames físico, laboratoriais (hemograma, alanino aminotransferase e creatinina) e radiográfico da pelve e do tórax, com o objetivo de se avaliar o comprometimento ósseo e pesquisar a presença ou não de metástase pulmonar. As radiografias do tórax foram realizadas em três incidências (ventro-dorsal, lateral esquerda e direita).

Para a realização da biópsia incisional, após as avaliações pré-operatórias os animais receberam cloridrato de levomepromazina ${ }^{1}$ na dose de $1 \mathrm{mg} / \mathrm{kg} /$ via intravenosa (IV) como medicação pré-anestésica, seguido da indução anestésica com propofol ${ }^{2}$ na dose de $4 \mathrm{mg} / \mathrm{kg}$ (IV) e manutenção com isoflurano ${ }^{3} \mathrm{em}$ oxigênio a $100 \%$. Em seguida o paciente foi contido em decúbito lateral e após a preparação do campo operatório, foi iniciada a abordagem cirúrgica. Para isso incisou-se a pele e tecido subcutâneo, afastaram-se os músculos regionais, obtendo-se assim acesso aos ossos da pelve. A biópsia óssea foi realizada com agulha de Jamshidi. Na seqüência, reconstituiu-se o tecido subcutâneo com sutura contínua simples com categute simples ${ }^{4} \mathrm{n}^{0} 2-0$, enquanto que para a pele optou-se por suturas interrompidas simples com mononáilon ${ }^{5}{ }^{\circ} 0$ ou 2-0. Os fragmentos ósseos obtidos foram colocados em frascos contendo formol $l^{6}$ a $10 \%$ e encaminhados para exame histopatológico.

Como principais afecções que compunham o diagnóstico diferencial, levouse em conta a pesquisa para neoplasia metastática óssea, osteomielite bacteriana ou fúngica e reações periosteais traumáticas. As avaliações que fundamentaram o diagnóstico, compreenderam o exame de citologia aspirativa, biópsia incisional e histopatologia.

\section{Resultados}

Nenhum agente etiológico foi relacionado com o desenvolvimento destas neoplasias e também não se observou predisposição hereditária no desenvolvimento deste tumor. Dentre os ossos que compõem a pelve se observou o OSA acometendo o ílio (6 casos), região acetabular (1 caso) e tuberosidade isquiática (1 caso).

Com relação ao sexo pode-se observar uma maior incidência em fêmeas ( 5 casos) do que em machos (3 casos). Dos oito animais atendidos, observou-se uma freqüência maior nos cães da raça Rottweiler ( 3 casos $=37,5 \%$ ) e Pastor Alemão (3 casos $=37,5 \%$ ), seguido do Dobermann (1 caso $=12,5 \%)$ e Boxer $(1$ caso $=12,5 \%)$. Relacionando a casuística do osteossarcoma em cães com a idade foi observado maior predisposição ao desenvolvimento tumoral em animais com idade variando entre cinco e 12 anos.

Claudicação, impotência funcional de membro pélvico do mesmo lado da hemipelve neoplásica e dor foram os principais sinais clínicos observados nos pacientes com esta afecção neoplásica. Outros sinais observados foram apatia, anorexia, atrofia muscular e retenção urinária. O período de tempo de início dos sintomas até a busca por tratamento variou de duas a 16 semanas. Dos oito animais submetidos a radiografias torácicas somente um apresentava imagens sugestivas de metástases pulmonares. Na grande maioria dos animais (7 casos) encontrou-se estágio avançado de comprometimento ósseo na imagem radiográfica, evidenciado, principalmente, pela lise da cortical óssea (Figuras 1,2 e 3).

Tanto no transoperatório como no pós-operatório não se observaram sinais de complicações cirúrgicas para a obtenção das biópsias. Microscopicamente, essas neoplasias eram compostas de osteoblastos, osteóide, cavidade cística com sangue e revestidas por 


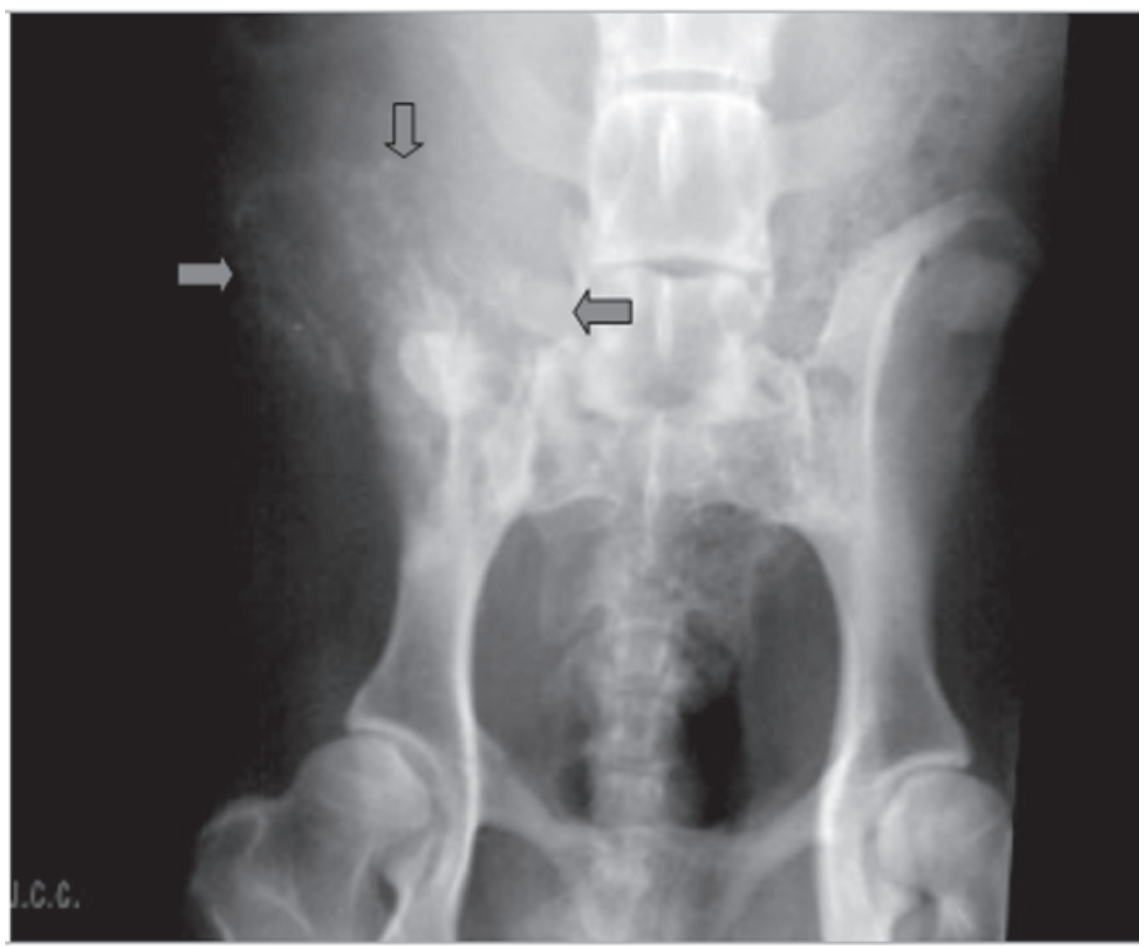

Figura 1 - Imagem radiográfica de um cão com osteossarcoma em crista ilíaca esquerda atendido pelo Serviço de Oncologia do Hospital Governador Laudo Natel, Universidade Estadual Paulista, campus de Jaboticabal - São Paulo, jun.2002. Notar a lise óssea nesta região (setas)

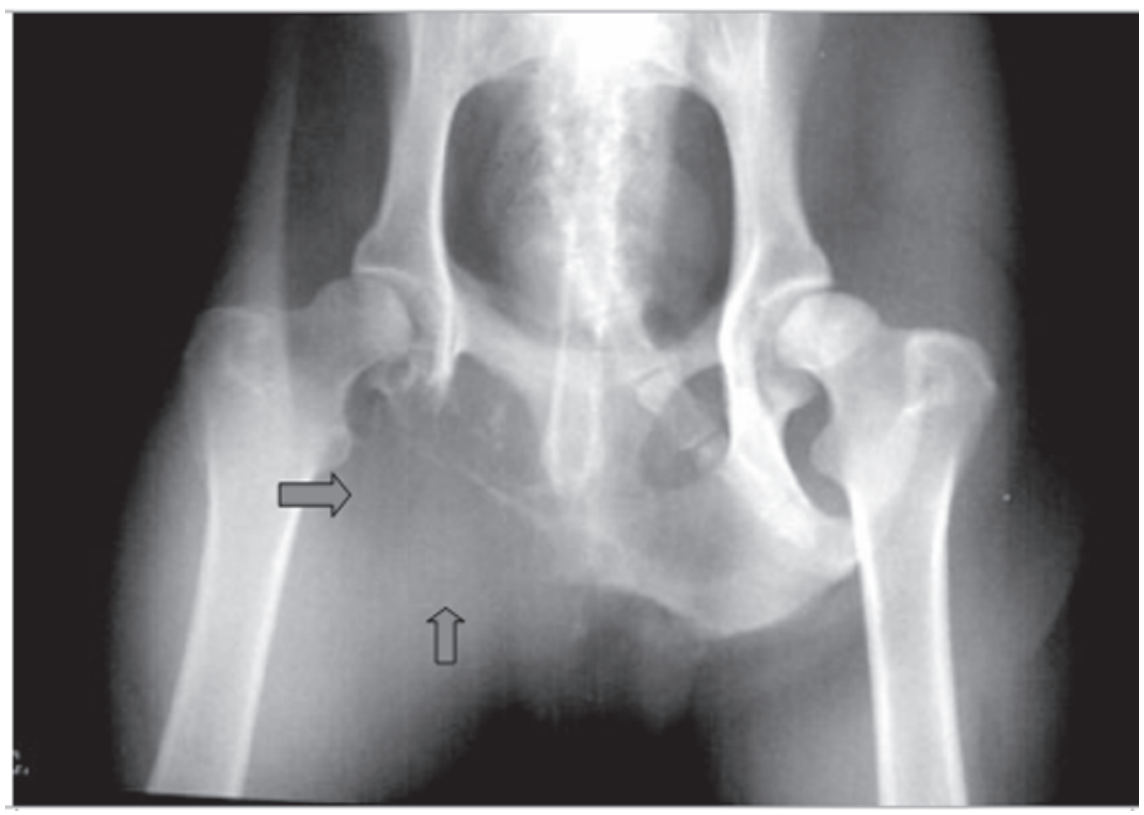

Figura 2 - Imagem radiográfica de comprometimento ósseo em tuberosidade isquiática esquerda resultante da evolução do osteossarcoma, em um cão atendido pelo Serviço de Oncologia do Hospital Governador Laudo Natel, Universidade Estadual Paulista, campus de Jaboticabal - São Paulo, jan.2003. Notar a lise óssea nesta região (setas) 


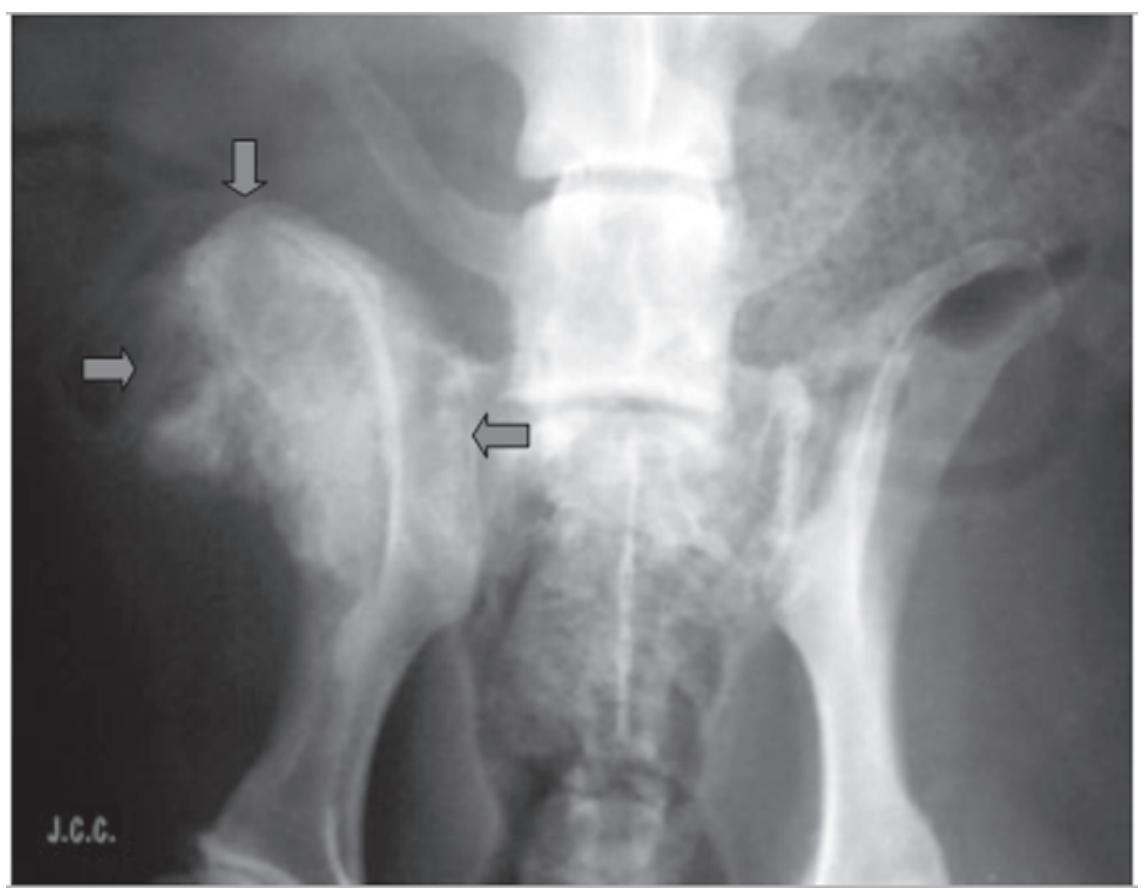

Figura 3 - Imagem radiográfica de severa reação óssea acometendo crista ilíaca esquerda, em um cão atendido pelo Serviço de Oncologia do Hospital Governador Laudo Natel, Universidade Estadual Paulista, campus de Jaboticabal - São Paulo, mar.2003. Notar a lise óssea nesta região (setas)

células malignas. Todos os animais foram submetidos à eutanásia, geralmente, 10 dias após a obtenção da biópsia, por não apresentarem possibilidade de tratamento cirúrgico (hemipelvectomia) com margem de segurança. Também se levou em consideração para esta decisão à condição clínica dos pacientes, as chances de conferir melhora na qualidade de vida dos cães e a opção dos proprietários frente ao prognóstico.

\section{Discussão}

O osteossarcoma é a neoplasia óssea mais diagnosticada no cão $\mathrm{c}^{2,3,4,5}$ sendo sua maior prevalência observada em animais de meia idade e idosos, conforme citado por Daleck $^{8}$, Haan e Brian ${ }^{9}, \mathrm{Ru}$, Terracini e Glickman ${ }^{11}$, Straw ${ }^{5}$, observação esta também constatada neste estudo. As raças que mais apresentaram esta neoplasia foram o Rottweiler e Pastor Alemão, o que vem corroborar com as observações de Liu ${ }^{10}$,
Ru, Terracini e Glickman ${ }^{11}$ e Spodnick et a ${ }^{12}$. Semelhante ao comentado por Dickerson et al. ${ }^{16}$, Heymann et al. ${ }^{13}$, as cadelas são mais acometidas por osteossarcoma do esqueleto axial em relação aos cães machos. Não foi possível correlacionar nenhum agente etiológico ou predisposição hereditária com o desenvolvimento desta neoplasia ${ }^{5}$.

A história clínica, exame físico, achados radiográficos, citologia e histopatologia foram fundamentais na definição do diagnóstico ${ }^{8,9,15,18}$. Os sinais clínicos observados no desenvolvimento do osteossarcoma em ossos da pelve foram os mesmos descritos por Dernnel, Straw e Withrow $^{3}$, Jourgeward ${ }^{19}$, Liu $^{10}$ e Straw ${ }^{5}$. A lise da cortical óssea foi a alteração óssea mais comumente encontrada nos casos de osteossarcoma, semelhante ao citado por Dernell, Straw e Withrow?

Segundo Spodnick et al. ${ }^{12}$ menos de $15 \%$ dos cães possuem sinais radiográficos de metástases pulmonares no momento da 
primeira consulta; freqüência semelhante $(12,5 \%)$ também observada durante a realização deste levantamento. Ao avaliar os dados encontrados em comparação com o levantamento realizado por Heymann et al. ${ }^{13}$, no qual num período de três anos foram diagnosticados sete casos de neoplasias ósseas de pelve, observou-se, neste estudo, uma casuística três vezes maior do que a encontrada por estes outros autores.

Conforme descrito por Straw ${ }^{5}$, às radiografias torácicas são importantes para definir o estadiamento da neoplasia, no entanto, um número muito pequeno dos animais apresenta metástases pulmonares no momento do diagnóstico ${ }^{12,17}$. As afecções descritas por Lang e Sulzbacher ${ }^{20}$, Lindenbaum e Alexander ${ }^{21}$, osteomielite bacteriana ou fúngica, infarto ósseo, osteopatia hipertrófica, hipervitaminose $\mathrm{A}$, reações periostais traumáticas e cistos ósseos aneurismais, devem ser sempre pesquisadas como diagnóstico diferencial no momento em que o médico veterinário suspeitar de uma neoplasia óssea. O diagnóstico definitivo foi o obtido pela biopsia incisional do tecido tumoral e histopatologia conforme o preconizado por Daleck $^{8}$, Straw e Withrow ${ }^{22}$, Straw, Withrow e Powers ${ }^{23}$, porém, as complicações pósoperatórias em decorrência da realização da biópsia, não foram observadas, contrariamente do que foi descrito por Straw ${ }^{23}$.

\section{Conclusões} concluir:

Frente aos resultados obtidos, pode-se

-Dentre os ossos que compõem a pelve se observou maior incidência de osteossarcoma acometendo o ilio.

-Os cães de raça grande apresentaram maior predisposição para o desenvolvimento do OSA em ossos da pelve.

-Claudicação, impotência funcional do membro pélvico, dor e apatia foram os principais sinais clínicos observados nos pacientes com esta afecção neoplásica.

- A realização da hemipelvectomia com margem de segurança ficou comprometida em virtude do estágio avançado de comprometimento ósseo observado na imagem radiográfica.

\section{Retrospective study of primary osteosarcoma in pelvis's bones of dogs during a period of fourteen months}

\begin{abstract}
The osteosarcoma (OSA) is one of the most common malignant tumors of dogs. Large and giant-breed dogs are affected and the mean age of these dogs is about 7 years. The tumor usually involves the metaphyses of long bones and the treatment is radical amputation and chemotherapy with cisplatin. The therapy of neoplasia located in pelvis is difficult and usually don't accept by owners. This report describes the incidence of primary osteosarcoma in pelvis of dogs, during a period of fourteen months. Of the eight animals taken care with this neoplasia, a bigger frequency in the dogs of the race Rottweiler and German Pastor was observed. Amongst the bones that compose animal's pelvis was observed greater osteosarcoma incidence in ileum (6 cases). Lameness, functional impotence of pelvic member and pain had been the main observed clinical signals. In seven cases was found advanced involvement osseous, mainly, for lyses of the cortical. All the animals had been submitted to the euthanasia for not presenting possibility of surgical treatment with safety margin. Also one was taken in consideration for this decision to the clinical condition of the patients, the possibilities to confer improvement in the quality of life of the dogs and the option of the owners' front to the prognostic.
\end{abstract}

Key-words: Neoplasia. Osteosarcoma. Pelvis's bones. Dog. 


\section{Referências}

1 HAMMER, A. S. et al. Prognostic factors in dogs with osteosarcoma of the flat or irregular bones. Journal of the American Animal Hospital Association, v. 31, n. 4, p. 321-326, 1995

2 DE MARTIN, B. W. et al. Isótopo terapia no tratamento de tumores ósseos, metástases e dor óssea. Clínica Veterinaria, n. 10, p. 31-34, 1997.

3 DERNELL, W. S.; STRAW, R. C.; WITHROW, S. J. Tumors of the Skeletal System. In: WITHROW, S. J.; MacEWEN, E. G. Small animal clinical oncology. 3 ed. Philadelphia: W. B. Saunders, 2001. p. 378-417.

4 JOHNSON, A. L.; HULSE, D. A. Other diseases of bones and joints. In: FOSSUM, T. W. Small Animal Surgery. 2. ed. Missouri: Mosby, 2002. p. 1168 - 1191.

5 STRAW, R. C. Tumors of the skeletal system. In: WITHROW, S. J.; MacEWEN, E. G. Small animal clinical oncology. 2. Philadelphia: WB Saunders, 1996. p. 378417.

6 McGLENNON, N. J. The musculoskeletal system. In: WHITE, R. A. S. Manual of small animal oncology. Worthing: British Small Veterinary association, 1991. p. 265-280.

7 THOMSON, R. G. Distúrbios circulatórios. In: Patologia veterinária especial. Rio de Janeiro: Guanabara Koogan, 1983. p. 90-143.

8 DALECK, C. R. Osteossarcoma canino. Clínica Veterinária, v. 1, n. 15, p. 26-27, 1996

9 HAAN, J. J.; BRIAN, S. B. The skeletal system. In: GOLDSTON, R. T.; HOSKINS, J. D. Geriatrics \& gerontology of dog and cat. Philadelphia: W.B. Saunders, 1995. p.291-313.

10 LIU, S. Tumores ósseos e cartilaginosos. In: BOJARAB, W. J. Mecanismos das moléstias na cirurgia de pequenos animais. 4. ed São Paulo: Manole, 1996. p.1037-1092.

11 RU, G.; TERRACINI, B.; GLICKMAN, L. T. Host related risk factors for canine osteosarcoma. Veterinary Journal, v. 156, p. 31-39, 1998.

12 SPODNICK, G. J. et al. Prognosis for dogs with appendicular osteosarcoma treated by amputation alone: 162 cases (1978-1988). Journal of American Veterinarian Medical Association, v. 200, p. 995-999, 1992.

13 HEYMANN, S. J. et al. Canine axial skeletal osteosarcoma: A retrospective study of 116 cases (19861989). Veterinary Surgery, v. 21, n. 3, p. 304-310, 1992.

14 NEWTON, C. D.; BIERY, D. N. Moléstias esqueléticas. In: ETTINGER, S. J. Tratado de medicina interna veterinária. 3. ed. São Paulo: Manole, 1992. v.
4. p. 2494-2517.

15 POOL, R. R. Tumors of bone and cartilage. In: MOULTON, J. E. Tumors of domestic animals. Berkeley: University of California Press, 1990. p. 157230.

16 DICKERSON, M. E. et al. Retrospective analysis of axial skeleton osteosarcoma in 22 large-breed dogs. Journal of Veterinary Internal Medicine, v. 15, n. 2, p.120-124, 2001

17 McENTEE, M. C. Palliative radiotherapy for canine apendicular osteosarcoma. Veterinary Radiology \& Ultrasound, v. 34, n. 5, p. 367-370, 1997.

18 LAMB, R. C. Preoperative measurement of canine primary bone tumors using radiography and bone scintigraphy. Journal of the American Veterinary Medical Association, v. 196, p. 1032-1037, 1990.

19 JONGEWARD, S. J. Primary bone tumors. Veterinary Clinics North America - Small Animal Practice, v. 15 , n. 3, p. 609-637, 1995.

20 LANG, S.; SULZBACHER, I. Differential diagnostic problems in assessment of benign bone tumors. Radiology, v. 41, n. 7, p. 533-539, 2001

21 LINDENBAUM, S.; ALEXANDER, H. Infections simulating bone tumors. A review of sub acute osteomyelitis. Clinical Orthopaedics, v. 184, p. 193203, 1984.

22 STRAW, R. C.; WITHROW, S. J. Limb-sparing for dogs with bone neoplasia. In: SLATTER, D. Textbook of small animal surgery. 5. ed. Philadelphia: W. B. Saunders, 1993. v. 2. p. 2020-2025.

23 STRAW. R. C.; WITHROW, S. J.; POWERS, B. E. Management of canine appendicular osteosarcoma. Veterinary Clinical of North American: Small Animal Practice, v. 20, n. 4, p. 1141-1161, 1990.

24 KIRPENSTEIJN, J. Canine osteosarcoma, is there a cure? (http://www. vin.com/proceedings/proceedings). Acesso em: 1 out. 2003. 